\title{
The Mechanical Dissection Laboratory: Educating Engineers for Industry
}

\author{
Jennifer L. Johrendt, Ph.D., P.Eng. \\ Assistant Professor, Mechanical, Automotive \\ \& Materials Engineering \\ University of Windsor \\ jennifer@uwindsor.ca
}

\author{
Peter R. Frise, Ph.D., P.Eng. \\ Professor, Mechanical, Automotive \\ \& Materials Engineering \\ University of Windsor \\ pfrise@uwindsor.ca
}

\begin{abstract}
In 1997-98 a major study was done to learn the expectations of Canadian industry for skills in new engineering graduates. It was found that while knowledge of mathematics and basic science was adequate, new graduates' knowledge of design, manufacturing and practical shop-floor knowhow was not. This study and similar US work by the ASME touched off several initiatives to address the deficiencies that were voiced by industry.

This research was used in founding the University of Windsor's undergraduate automotive engineering program in 1999 as Canada's first undergraduate level automotive education. The program was designed from the outset to incorporate a unique laboratory experience in the third year Automotive Engineering Fundamentals course. The goal was to provide an experience that would promote comprehension and retention through hands-on exercises that were practical to the field and valued by industry. In the Mechanical Dissection Laboratory $(M D L)$, students are assigned a single cylinder four cycle engine with which they work for the semester. Students run their engine and perform basic performance measurements before and after they dissect, examine and reassemble the unit. They measure key dimensional and operating metrics and investigate the materials and manufacturing methods, tolerances and stack-ups and issues such as assembly methods, tool access etc. Students have access to the manufacturer's drawings during their work and use their own tool kits as well as materials provided by the course instructional staff.

The development and operation of the MDL is the focus of this paper. The authors describe the origin of the Lab, its inspiration from a similar facility at the University of Karlsruhe, the philosophy and rationale of the Windsor MDL, design and equipment in the Lab
\end{abstract}

and some reflective comments looking back over the ten years since its inception in the program.

\section{Introduction}

Being a successful engineer requires more than a degree in engineering. Industry needs well-rounded engineers who are professionally, socially, and personally competent and who possess a strong set of ethical values. Development of a non-technical (complementary) skill set in undergraduate students can take place during their university education through a carefully planned curriculum that incorporates activities in environments designed to develop these skills.

The Canadian Engineering Accreditation Board $(\mathrm{CEAB})$ requires that engineering programs must actively develop a set of twelve graduate attributes. Half of the attributes listed in the 2009 Accreditation Criteria Procedures [1], can be categorized as complementary skills:

- Individual and team work

- Communication skills

- Professionalism

- Impact of engineering on society and the environment

- Ethics and equity

- Life-long learning.

In as much as elements of these attributes can be taught, students must also take responsibility for their professional development. Taylor [2] is currently performing work to incorporate independent student learning and peer teaching as key components in their learning and development.

Undergraduate engineering curricula are not only driven by the professional governing bodies, but also by industry and the needs of the global economy. The role of the design engineer has been developing as companies accommodate new technologies and leaner operating structures [3], [4], [5]. That fact, in 
conjunction with the evidence to support that industry surveys support the development of the complementary skill set [5], [6], inspired the development of the MDL as focal point of the Automotive Engineering Option program at the University of Windsor in 1999. It can be noted that the MDL directly addresses three of the top ten deficiencies in new graduates identified by industry as reported by May and Strong [6]: practical skills, communication skills, and teamwork.

Since the development of the MDL, the value of the lab as an experiential learning tool in reinforcing knowledge in the affective domain (i.e. teamwork, effective communication, ethics, safety, creativity and the ability to learn from failure) has been described through exercises performed in the MDL [7].

Faisal and Rosa [8] emphasized the need for instructional laboratories in undergraduate engineering programs for the purpose of "learning something that practicing engineers are assumed to already know" [8], where hands-on experiments are the focus of such learning. Kolb describes hands-on learning activities as a method by which learners' interaction with their learning environment is enhanced [9].

\section{Universät Karlsruhe - the inspiration for the MDL}

During the formative phase of the Automotive Engineering program at Windsor, a global benchmarking exercise of leading industry-academic collaborations and design engineering education programs was undertaken. A great many interesting and novel approaches were found in many locales but most were variations on the typical design project and lecture materials which nearly all mechanical engineering students receive in accredited programs.

Based on the extensive study of the skills needs for mechanical engineers found in the industry study described above and the clear emphasis placed on enhancing the practical skills and knowledge of students, particular attention was placed on programs that gave their students opportunities to move out of the traditional academic mode of lectures and notetaking into a more hands-on learning format. The best program found in that respect was the Mechanical Engineering program at the Universät Karlsruhe in Germany. The head of the program, Dr-Ing. Albert Albers had set up a lab in which his students worked together in groups of about four on the examination, disassembly and reassembly of a small singlereduction gearbox. The students were required to make sketches and learn about the production methods of each component in the gearbox and then prepare reports on their findings. Dr. Albers stated that the lab worked quite well but he felt that it could be even better if the following changes were made:

- Each student should have their own machine to ensure that each worked with their hands rather than merely observing others;

- A machine that actually runs would be a better choice that a simple (and rather inert) gearbox.

The MDL at Windsor was developed along these lines bearing in mind the final two points learned from the lab at Karlsruhe.

\section{MDL Development at Windsor}

Dr. Gregory Rohrauer (now at UOIT in Oshawa, ON) and Dr. Peter Frise designed the MDL during the development of the Automotive Option program at the University of Windsor in 1999. In keeping with the automotive theme and the advice of Dr. Albers of Karlsruhe, the specimen used in the Windsor MDL is a single cylinder four cycle $170 \mathrm{cc}$ engine typically found in small garden machines. Nearly 100 of these engines along with a set of shop drawings have been provided by Linamar Corp. of Guelph, ON.

Physically the MDL is outfitted with waist-height work surfaces along three of the outside walls and two more lengths of countertop workspaces along the length of the centre of the room. Each workspace has a compressed air supply and an electrical receptacle. Lockable cupboards beneath the benches allow students to store their personal tools along with their engines and associated documentation (service manuals, laboratory manuals, etc.). The room can accommodate approximately twenty-four students during each laboratory session.

There are shelves and lockable storage cabinets along the remaining wall for parts storage and additional automotive components. Occasionally, these parts are examined by the class as they relate to the lecture material throughout the semester. The walls of the room are lined with the manufacturer's drawings, enlarged to approximately 3' $x$ 4' for ease of viewing. The drawings are mounted on foam core board and secured to the wall. Some drawings are displayed more than once so students can access them easily during group discussions led by the instructor.

There is also a blackboard in the room that is used for instructional purposes and sample calculations.

\section{MDL today}

\subsection{The course}


The MDL is used as the focal point for the third year course Automotive Engineering Fundamentals (0694330). It is the first course taken by newly declared Automotive Option students in the Mechanical Engineering program at the University of Windsor.

The course serves as an introductory overview of automotive systems such as engines, transmissions, driveline, suspension, and brakes. Each week there is one hour and fifty minute lecture and one two hour and fifty minute laboratory session.

Besides the automotive systems content, lectures also include the history of the automobile, an introduction to Geometric Dimensioning and Tolerancing (GD\&T), and invited presentations about automotive related research topics by professors in the department. Topics have included automotive industry trends, vehicle crash and safety, steel tube hydroforming, and mechatronics. The guest lectures provide insight into automotive research at the University of Windsor and has also promoted life-long learning of the students as they are encouraged to consider graduate studies and research in these areas.

\subsection{The laboratory}

At the beginning of the semester, students complete an experiential profile survey to assist the instructor in assigning lab partners. The goal is to pair students that have more previous hands-on automotive experience with those having less experience of that nature (Figure 1). This pairing is used to promote peer teaching in the laboratory environment. The practice of working in pairs began during the year that the double cohort of students came through the program, when enrolment was very high due to additional secondary school graduates in the post secondary system. The practice has continued since to incorporate peer instruction into the laboratory exercises.

Over the length of the 13-week semester, the engines are run, disassembled, reassembled, and then run again. While operating the engines at the beginning and end of the semester, engine noise levels, emissions, temperatures, and speed are measured at various operating conditions (e.g. idle, full throttle) and the students are instructed on operating adjustments of the engines.

Various engine component measurement tasks are also performed throughout the semester during various stages of engine disassembly (Figure 2). The manufacturer's bill of materials and drawings are available in the MDL as well as electronically on the course website. Tolerance stack-up and surface measurements are examples of the exercises that the students complete using the GD\&T lecture notes.
Figure 1. Students work in pairs to dissect and reassemble the engines.

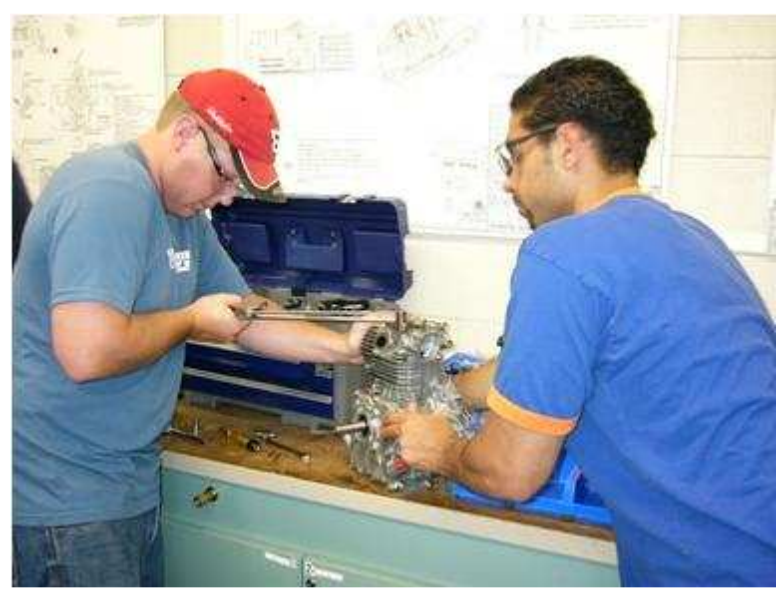

Figure 2. Students measure parts and have access to the manufacturer's drawings.

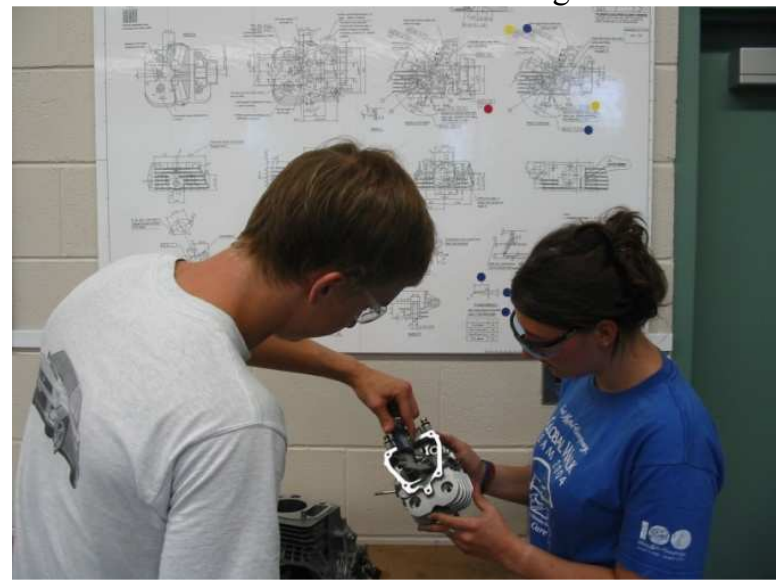

Graduate assistants (GA's) are present in the laboratories with the course instructor. It is not uncommon that each year one or more of the GA's selected to work in the MDL have completed the course as an undergraduate student. This helps with the transference of tacit knowledge during the laboratory sessions.

In addition to the academic knowledge acquired in the course, students also have the opportunity to work on their written communications skills and research relevant topics of interest, submitting a written review of a technical paper of their choice. This task proves interesting, as students at this stage of their education have rarely searched for or read journal papers in the University's library system.

Throughout the semester, by completing the tasks described in the intimate setting of lab sections with no more than 24 students, CEAB graduate attributes are developed, including individual and team work, 
communication skills, professionalism, impact of engineering on society and the environment, ethics and equity, and life-long learning.

To date, student feedback from the course has been positive and, despite some anxiety, students show great pride when they successfully start their engines following the reassembly task.

I can't believe how much theory I take before I even touch an engine. I know all about the theory of operation inside and out without ever touching an engine, but I still learn so much more in this course.

I have learned so much in this course. Being able to take this engine apart and put it back together has taught me so much.

This is one of my favourite courses.

Third-year University of Windsor Automotive Engineering students, 2006

In addition, students going on to enrol in graduate studies at Windsor following their graduation will often request the opportunity to serve as one of the GA's for this course.

\section{Looking ahead}

As this paper is written, a new building for the Faculty of Engineering is under construction at Windsor: the $30,000 \mathrm{~m}^{2}$ Centre for Engineering Innovation. The CEI will house an additional MDL, similar to the original lab located in the Centre for Automotive Research and Education (CARE) with the addition of an overhead projector and white board. In this way, interactive information can be displayed to the class as questions arise during the laboratory sessions. It would also open up the opportunity for projecting a scope camera image of the internal features of an engine during the class, for example.

The University of Windsor's Automotive graduates are well-received by employers. In fact, students repeatedly demonstrate their practical knowledge in industry during co-operative education placements with automotive companies located around the world. Feedback from employers has been positive and it is not uncommon for employers to request these students for extended work term placements each year.

Recently, the laboratory has been incorporated into a similar course offered as part of the Master's of Engineering program in Automotive Engineering offered through the University of Windsor's Centre for Executive Education. Course registrants are primarily international mature students who are enrolled in the one year course-based professional program. Increasingly, students opt to participate in a cooperative education component where the hands-on benefits of the MDL can serve to introduce them to laboratory safety and communications skills.

The authors believe that the benefits of such a lab component in undergraduate engineering courses could and should be extended to students in other courses such as machine design where laboratory sessions could be incorporated to dissect mechanical assemblies to illustrate specific operational principles being studied in the lectures such as gears, bearings, and clutches, for example.

\section{References}

[1] Canadian Council of Professional Engineers, 2009 Canadian Engineering Accreditation Board Accreditation Criteria and Procedures, Canadian Council of Professional Engineers, retrieved from

http://www.engineerscanada.ca/e/files/Accreditation_Criteri a_Procedures_2009.pdf, May 2010.

[2] P. Taylor, "A new way of teaching”, Queen's Alumni Review, 1, 2010.

[3] P.R. Frise, G.L. Rohrauer, B.P. Minaker, W.J. Altenhof, "Identifying the Design Engineering Body of Knowledge", International Conference on Engineering Design (ICED), Stockholm, August 19-21, 2003.

[4] P.R. Frise, "The Challenge of Staying Current in Today's Automotive Industry for the Design Engineer", $8^{\text {th }}$ World Congress on Continuing Engineering Education, Toronto, May 12-16, 2001.

[5] P.R. Frise, M.D. Sirizzotti, R.G. Gaspar, G.T. Reader, "Mechanical Engineering Skills Needs in Canadian Industry”, CSME Annual Conference, Kingston, May 2002.

[6] E. May, D.S. Strong, "Is Engineering Education Delivering What Industry Requires?", 3rd CDEN/RCCI International Design Conference, Toronto, July 24-26, 2006.

[7] J.L. Johrendt, D.O. Northwood, "The role of the instructional laboratory in the development of knowledge in the affective domain: an example from automotive engineering", $5^{\text {th }}$ Global Congress on Engineering Education, Brooklyn, July 2006.

[8] L.D. Faisal, A.J. Rosa, "The role of the undergraduate laboratory in undergraduate engineering education", Journal of Engineering Education, 121-130, January 2003.

[9] D.A. Kolb, Experiential Learning: Experience as the Source of Learning and Development, USA: Prentice Hall, Englewood, Cliffs, 1984. 